\title{
The High Benefits Internet Marketing Framework through Customer Experienc
}

\author{
Nai-Wen Kuo ${ }^{1}$ An-Yi Liu ${ }^{1}$ \\ ${ }^{1}$ Graduate Institute of Information Management, Chinese Culture University
}

\begin{abstract}
This paper is intended to integrate Internet Marketing, Customer Experience, E-brand and Integrated Marketing Communications to develop a high benefits Internet Marketing Framework. This framework not only can combine marketing resources effectively, let enterprises obtain the greatest benefits; it also provides total consumer experience and increase customer satisfaction. On the other hand, this making a more successful customer relationship management and customer experience on internet marketing can be achieved. Furthermore, we make the application of internet marketing will be more extensive and convenient.
\end{abstract}

Keywords: Internet Marketing, Customer Experience, E-brand, Integrated Marketing Communications.

\section{Introduction}

The Internet is a significant global medium for communications, content and commerce. It is a powerful tool for building relationships with all of a company's communication targets. It is cheep, Immediate and repeatable with appropriate technology it can be personalized. Online purchases by both businesses and consumers are booming. SO, it is important to let enterprises obtain the great benefits and increase customer satisfaction. The aim of paper is to develop the Internet Marketing Framework achieving high benefits through customer experience.

\section{Internet marketing characteristics}

Internet Marketing (IM) is a field which is continuing to grow. Its characteristics as follows
(Eric and Ferry,2001 ; Riyad and Myfanwy, 2002 ; Roger, James and Ghada,2003 ; Kuo and Liu,2005 ) :

(1) Global reach

The Internet helps business reach the whole world.

(2) Real-time access

The Web makes it possible for customers to interact immediately.

(3) Information density

The technology reduces information costs and raises quality.

(4) Richness

Multimedia and information can become vivid.

\section{Integrated Marketing Communications}

Integrated Marketing Communications (IMC) is capable of enhancing the holistic consumer experience and creating a holistic brand value structure, which can unite the consumer's sensory, emotion, social and intellectual experiences.

( Don,Rober,Stanley,1994,Don,Heidi,2004,Chen -linChen,2004,Shu-peiTsai,2005 ):

(1) Put consumers in core of marketing strategy.

(2) Pay much attention to Brand strategies.

(3)Establish long-term relationship between enterprise or brand and consumers.

(4)Using more information technologies be marketing tools.

(5) Integrate communication tools.

\section{Customer Experience}

Customer Experience (CE) is some feeling and experiences customers got through shopping process (Lewis Carbone,2004).

Schmitt (2000) proposed the Strategic Experiential Model as shown in table 1. 
Table 1 The strategic experiential model, Schmitt (2000)

\begin{tabular}{|l|l|}
\hline Element & \multicolumn{1}{|c|}{ Define } \\
\hline Sense & $\begin{array}{l}\text { The experience model excites by } \\
\text { senses. }\end{array}$ \\
\hline Feel & $\begin{array}{l}\text { Making consumers stir up emotions } \\
\text { by some experiences. }\end{array}$ \\
\hline Think & $\begin{array}{l}\text { Often encouraged consumers } \\
\text { creativity and estimated enterprises } \\
\text { and product. }\end{array}$ \\
\hline Act & $\begin{array}{l}\text { Design long-term interaction model } \\
\text { with consumers. }\end{array}$ \\
\hline Relate & $\begin{array}{l}\text { The interacted from person to person } \\
\text { will make some powerful } \\
\text { relationship. }\end{array}$ \\
\hline
\end{tabular}

\section{The High benefits Internet Marketing framework}

This paper combine "Interactive customer experience framework" ( Nai-Wen Kuo , An-Yi Liu,2006), "Strategic Experiential Model ,SEMs" ( Schmitt, 2000 ), the strategies of Internet and IMC theory to develop a high benefits Internet Marketing framework. This framework including three main process "Making Strategy", "Executing Communication" and "Becoming Connection", as shown in Figure 1.

\subsection{Making Strategy}

The "Interactive customer experience framework" (as shown in Figure 2) is core of the Making strategy and connects with the Strategic Experiential Model's elements-- "Feel", "Think" and "Act".

The system can use the primal data in customer experience making the life styles, product trend and brand meaning with products' plan. The Website can both have whole strategy planning, changeful user interface and meet different consumers' customer experience through creating the situation, brand stories and social cultures. The following is a brief description of interactive customer experience framework.

\section{Building E-brand strategy through the feel.}

Through communication of brand story, symbol meaning and life style can provide consumers some brand feeling, experience and emotions.

\section{Using the think helps continued creativeness}

Making customers' creativity together and blending into development of products, brand design and experience model's creativeness can help enterprises' strategies to achieve consumers' need. Beside, continued creativeness not only bases on customer opinions change their strategies but put them into Website continued business plan.

\section{Using the Act designs interactive customer experience center}

Interactive customer experience center sets up long-term behavior model and life style with consumers. Using the Act designs interactive customer experience center not only analysis single customer's characteristics and same points in group customers but also make the rules classifying customers and distinguishing customer's type in the short time. In addition, information technology could help creating new experience models by automatically.

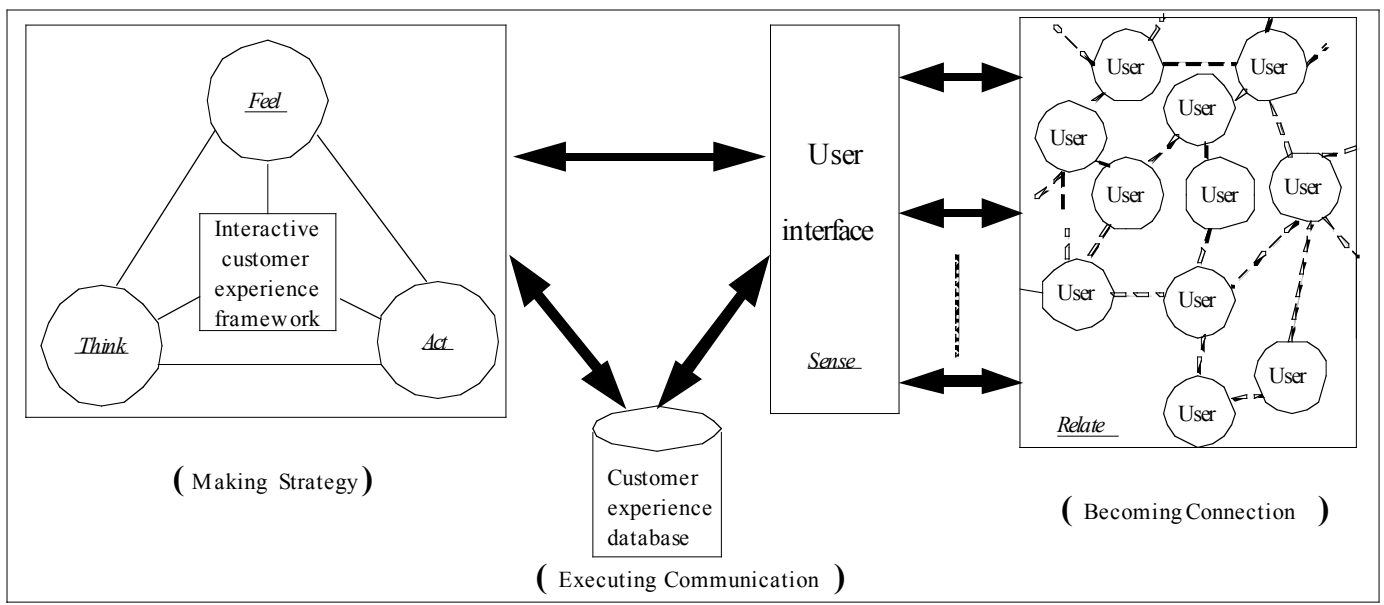

Figure 1 : High benefit mix Internet Marketing framework 


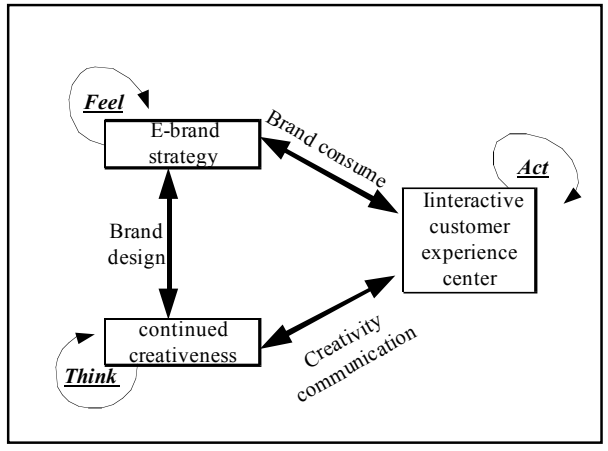

Figure $2:$ Interactive customer experience framework emotions.

\subsection{Executing Communication}

Website will pass the specially experience situations, product information and contents of services with consumers through the user interface and activated contact. The Sense can provide some stimulus from touching, vision or hearing. Using some information technologies we can collect and store up customers' transaction data. Those data will be provided to analyze customers' experience or build up creativeness strategies. Executing Communication has two main blocks including "User interface" and "Customer experience database".

\section{User interface}

User interface is a medium interact with consumer. There are some functions could supply different experience model to excite person's senses and to make movement revises. According to every customer's commands that a quite important information in this framework

\section{Customer experience database}

The most impartment function of Customer experience database is keeping whole customer's basic information, liking, characteristics and bargain information. These will provide framework tom analyze customer experiences or other applications.

\subsection{Becoming Connection}

Becoming connection is creating the relationship between Website and users. Collocating with the Strategic Experiential Model's elements-- "Relate" could connect with personal experience, brand culture, social values and group opinions to establish power of interaction in each element.

\section{Connection between consumers and Website}

In connection between consumers and Website, if consumers search some information or services voluntarily those have more powerful interrelationship, effectiveness and higher relation. On the contrary, if consumers is passive behaviors that some relationship between consumers and Website are both weakly.

\section{Connection between consumer each others}

If the consumers exchange information by Website's group or interpersonal relationship could help creating connection actively then great interrelationship will be exist. Though some group's activities could add additive values.

Integrated marketing resources are important in Internet Marketing. This framework is using the IMC theory to make sure "Communication Integrate" and "Set up relationship" from inside to outside (Mix system function in Figure 3 ). Communication Integrate strategy is between Making Strategy and Executing Communication, that making consumers get a suitable experience model's clearly and signal images, orientation, messages and topic by different communication ways. Set up relationship strategy is between Executing Communication and Becoming Connection. Its main mission is creating the website or brand's long-term relationship with consumers. Great relationship can push customers shopping again and raise their loyalty.

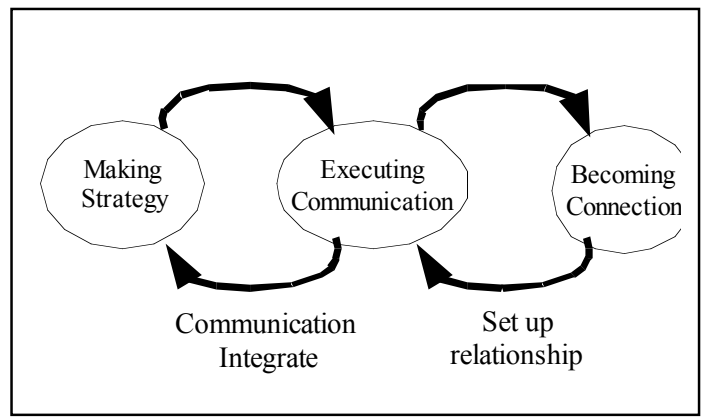

Figure 3 : Mix system function

\section{Conclusion}

The Internet is a significant global medium for communications, content and commerce. It is a powerful tool for building relationships with all of a company's communication targets. This paper is intended to integrate Internet Marketing, Customer Experience, E-brand and Integrated Marketing Communications to develop a high benefits Internet Marketing Framework. This framework not only can combine marketing 
resources effectively, let enterprises obtain the greatest benefits; it also provides total consumer experience and increase customer satisfaction. Furthermore, we make the application of internet marketing will be more extensive and convenient.

\section{References}

[1] Al Ries \& Laura Ries, The 11 Immutable laws of Internet Branding, Harper Collins Publishers, Inc., USA, 2000.

[2] Bernd H. Schmitt, Experiential Marketing: how to get customers to sense, feel, think, act and relate to your company and brand. Big Apple Tuttle-Mori Agency, Inc, 2000.

[3] Bernd H. Schmitt, Customer Experience Management - A revolutionary approach to connecting with your customers, John Wiley \& Sons, Inc. 2003.

[4] Chen-lin Chen, The Effect of Integrated Marketing Communication on the Brand Image of Automobiles. , Chaoyang University of Technology. Department of Business Administration for the Degree of Master. 2004.

[5] Don E .Schultz, Rober F . Lauterborn, Stanley I. Tannenbaum, Integrated Marketing Communications - Pulling it Together and Making it Work, NTC Publishing Group. 1994.

[6] Don E .Schultz, Heidi Schultz, IMC-the next generation: five steps for delivering value and measuring financial, The McGraw-Hill Companies, Inc. 2004.

[7] Eric Allen and Ferry Fjermestad ,E-commerce marketing strategies : an integrated framework and case analysis, Logistics Information Management, 14(2), pp. 14-23. 2001.

[8] Lewis Carbone, Clued In. Business News Publishing Ltd .2004.

[9] Nai-Wen Kuo, An-Yi Liu, The integrated internet marketing framework of interactive customer experience, Working Paper, Taipei, Chinese Culture University. 2006.

[10] Nai-Wen Kuo, An-Yi Liu, The application of integrated marketing communications on the framework of internet marketing , 2005Taiwan conference on Management and Decision, Nanhua University, 2005.

[11] Riyad Eid \& Myfanwy Trueman, The Internet : New International Marketing Issues, Management Research News. 25(12), pp.54-67. 2002.

[12] Roger Darby James Jones and Ghada AI
Madani ,E-commerce marketing : fad or fiction? Management competency in mastering emerging technology, An international case analysis in the UAE, Logistics Information Management, 16 (2),pp.106-113,2003.

[13] Shu-pei Tsai, Integrated marketing as management of holistic consumer experience, Business Horizons 48,pp431-441,2005. 